\title{
PAPERLESS AND CASHLESS DIGITAL PAYMENT METHODS
}

\author{
A.Venkatesh Boopathy \\ Lecturer, Modern Office Practice, \\ V.S.V.N.Polytechnic College, Virudhunagar
}

\begin{abstract}
A PC world is the face of India to enhance the country economy. PC is the abbreviation of Paperless and Cashless Transactions. Digital world is the future of India in the pace of developed country. A paperless \& cash less transaction are the key motto of digital payment. It is also among one of the nine pillar initiated by Indian Government to make India a developed country. There are many methods for PC transactions. This paper reveals the comparison between the traditional model and UPI model of online transaction which is a step ahead than internet banking and card payment methods. Levels of transaction are clearly defined. E- Wallet is also an essential payment model in real practice for PC transaction. Various banking \& private Institution are providing these facilities and abide the legitimate government. Future scope of digital payment is broad and quick-witted to enhance countries socio - economy relationship between of enterprises and organizations and end user towards a paperless less and cash less transaction.
\end{abstract}

Keywords : Online Transaction, Traditional transaction Model, UPI, E- Wallet, Future Scope

\section{INTRODUCTION}

Earlier in India there is a Barter System. In Barter System people generally use less monetary transaction. Marketing involves exchange of goods. One item or product can be bought in exchange of other item without any delay. It is a multilateral exchange where two parties are involved in a buying and selling process. The reason behind this cashless transaction is inadequate supply of money on a particular time. The same concepts have been proposed by Indian government to support paperless and cashless transaction, but the reason is not a short supply of money, rather it assure security of common man and also a corruption free society. Direct cash transaction may lead to looting of money, lot of paper work, shortage of money on demand; time is a major constraint which restricts the use of financial transaction also. These drawbacks are avoided by paperless and cashless system of financial transaction. This PC system is into practice from last couple of years powered by Net. This is the era of Smart phone; with one app we can do PC transaction any time and PC transaction are not only safe but also economical both in financial and non financial perspectives.

\section{WHAT IS ONLINE TRANSACTION?}

When money transitions are done by power of internet it is termed as online transaction. It require an end user account which credit or debit money at source or sink. It is a password protected transaction processing method which transfer money on users request (login in). The key goals of online transaction are consistency, reliability, availability, concurrency and recoverability. It supports paperless \& cashless transaction with high throughput. Also referred as Online transaction processing (OLTP) in terms of transaction database management.

\section{Features of Online Transaction.}

Data Consistency: Data are stable in nature and it cannot be changed without proper authentication.

Data Integrity: Data's are in pristine condition, all the histories and update information are stored and available on requirement.

Durability: Data's resists for longer period of time.

Atomicity: Data's accessed via any medium are provided to user as all or not at all.

Data Availability: All users' record must be available on users profile which helps in transaction at every level.

\section{Security}

Security is one of the key feature in online transaction Card Holder's are sharing there valuable information with the merchant website. So it is the responsibility of the merchant website that it should not be disclosed or hacked by any means. The system developed for online transaction must provide highly secure and risk free transaction. Every Card Details must be encrypt through the payment gateway. The payment gateway (browser) authenticates the access of legitimate user having the PIN or a user defined password. It is also secure with the feature of OTP generated by the system to protect the transaction of the end user. 
Level 7: The amount is debited from payers account and transaction is maintained in bank log. The transaction is logged as COMMITED.

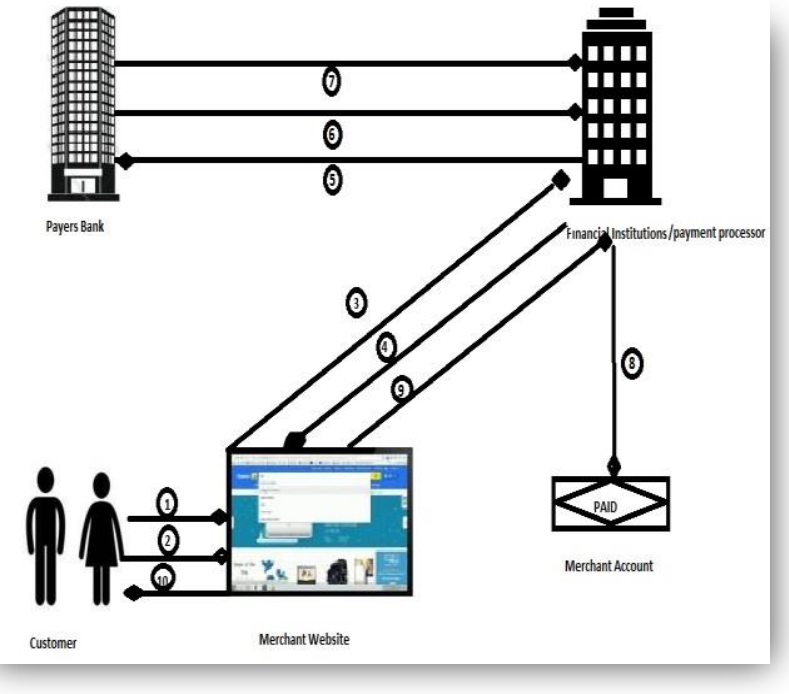

\section{TRADITIONAL PAYMENT MODEL}

Figure 1: Traditional Payment Model

Online transactions are done with the help of payment processor or financial institutions. This is the intermediary's bodies which govern the transaction for both payer's bank and merchant bank. Below figure 1 represents the online payment framework which shows the involvement of financial institutions in between payer's bank and merchant bank. The rise and persistence of online payment is still an option available with many merchant websites.

Level 1: Whenever a customer wants to pay online through a merchant website it has to login with accurate credentials.

Level 2: Product is selected for payment followed by an online payment mode

Level 3: Online payment mode links to merchant website or redirect the page to the payment gateway also referred as payment processors.

Level 4: The payment gateway ask for a customer credential such as 16 digit card number cardholder name, expiry/validity date, cvv number or pin for credit and debit card transactions and username and password for internet banking, both mode leads to OTP generation for completing the transaction.

Level 5: After the credentials are provided by the customer the financial institutions share the information with the payer's bank to authenticate the data's provided by the user and for checking the availability of fund in payers account. If the fund is insufficient the operation is rejected by the payer's bank, and the transaction is ABORTED

Level 6: If payers bank permit the availability of fund then the financial user gets authorization for completing transaction. It is logged as PARTIALLY COMMITTED
Level :8 The amount is credited to merchant amount and transaction is maintained in merchant log. The transaction is logged as COMMITED once again in Merchant log.

Level 9: A payment summary displayed on the payee screen and financial Institution acknowledge a message to the customer as "Payment completed successfully".

Level 10: Transaction is completed and customer log off.

$$
\text { IV. UPI }
$$

Unified Payment Interface is the simplified approach for e- payment where transaction are made without entering debit card numbers, cvv, pin customer name and other details.

Unified Payments Interface (UPI) is remarkable swift payment solution developed by a RBI regulated body NPCI. NPCI stands for National Payments Corporation of India. UPI allows two multilateral parties to participate in instant money transfer with a valid bank account and UPI PIN. UPI- PIN act as a key to authenticate and authorize all bank transactions. It works $24 / 7$ irrespective of the bank working hours. Every transaction can be made by providing a payer account details and a payee account details required for fund transfer. One account and UPI Pin can help payment system faster and quicker.

How to use UPI

- An UPI app can be downloaded from Google play store if released by respective banks.

- If your mobile number is registered with bank account, a sms will be automatically sent to bank.

- It will next ask for "DO you want to continue with this mobile number" Yes or No.

- After clicking on YES, It will ask for virtual address (email address@bank name), and general profile information .

- Virtual address is a unique name which acts as an identifier to access your account detail.

- You also have to select a bank and click on agree and then, click next.

- The next page displays a profile detail (entered by the user), it also shows the customer account number by default, then click on Register.

- Registration process is successfully completed

- Next it will ask to set a password for login.

- You also have to set a UPI PIN by entering the debit card information once for all transaction.

- Next it will ask to set the MPIN. The full form of MPIN is 'Mobile banking Personal 
Identification number. It helps for payment every time.

- Payment can be done by giving a virtual address or account number to whom you want to transfer the amount, and MPIN.

- You can transfer up to Rs. 1 Lakh per single transaction.

\section{LEVELS OF TRANSACTIONS}

Level 1: Customer login to merchant website with proper credentials.

Level 2: Customer selects UPI mode/option for online payment.

Level 3: Customer select bank and provides virtual address to access the transaction rights.

Level 4: After the credentials are provided by the customer, the payer's bank authenticate the data's provided by the user and for checking the availability of fund in payers account. If the fund is insufficient the operation is rejected by the payer's bank, and the transaction is ABORTED, and If payers bank permit the availability of fund then it sends an MPIN to the customer mobile number for completing the transaction. It is logged as PARTIALLY COMMITTED

Level 5: After the correct pin is provided by the customer the payers bank immediately debit the the amount from customer account, It is logged as COMIITED.

Level :6 The amount is credited to merchant amount and transaction is maintained in merchant log. The transaction is logged as COMMITED once again in Merchant log.

Level 7: A payment summary displayed on the payee screen by merchant website and it acknowledge a message to the customer as "Payment completed successfully". Transaction is completed and customer log

$$
\text { V. E- WALLET }
$$

Wallet is software designed to allow financial transaction in a easy mode. It is also referred as E- Wallet as transaction is made online electronically. A user has to create a profile identified by a password, with all the details of debit card, credit card, and account related information for future use. With Ewallet, user can make payments for online purchases of any items, such as ticket (flight/movie/rail/show), digital product, grocery items, medicines, appraisal e.t.c. The user account information is protected by password. The information are encrypted and highly secured. Many banks provide e wallet facility now days of their own to cope up with private e wallet companies. There are e wallets also which can be downloaded by Google play. Various private companies provides E wallet where money can be added from bank account for online purchase. If bank authorizes the payment then it is credited to $\mathrm{E}$ wallet account. E-wallet can store money for future use and have same function but it must be linked to a bank account for its use. It also records and stores all the transaction made by user in the database. It is pre processed card where money is kept and used in right time and right place as per need. E wallet can be used for bill payments, fee payment, ticket booking, hotel booking, online shopping, money transfer and many more. Various private companies in India provide $\mathrm{E}$ wallet facility such as Paytm, Mobikwik M-Pesa, Citrus Wallet, Jio Money, etc. All these private E-wallet companies are abiding by the principle of RBI as well licensed by it for financial transition. They must work according to the legitimate government. The main objective of $\mathrm{E}-$ Wallet is to make PC transaction.

\section{SCOPE OF DIGITAL PAYMENT}

- To compact the use of traditional payment models.

- To enhance B2B, B2C, C2C and C2B e commerce potential for e payment and to develop customer intimacy

- To upgrade the skill set of user by exposure of latest technology.

- To make end user independent by exposure of technology.

- To reduce cash based transactions and provide cashless and paperless transaction.

- To increase the acceptance level in the country to promote digital payment transactions methods.

- To link business hub, institutions and merchant sites with the customer with a quick payment solution.

- To enhance the use of technology among all the generations.

- To reduce fraud risk, counterfeit, money loss and money laundering

- To provide a reliable and trusted payment solution in a fraction of seconds.

- To expose every citizens to fastest and secured online payment methods.

- E- transaction are inexpensive and inherently 4.

more scalable, and can handle a much greater transaction volume of data.

- Customer can easily track records of their account, and transfer money online anywhere, any time and at any moment as per the need.

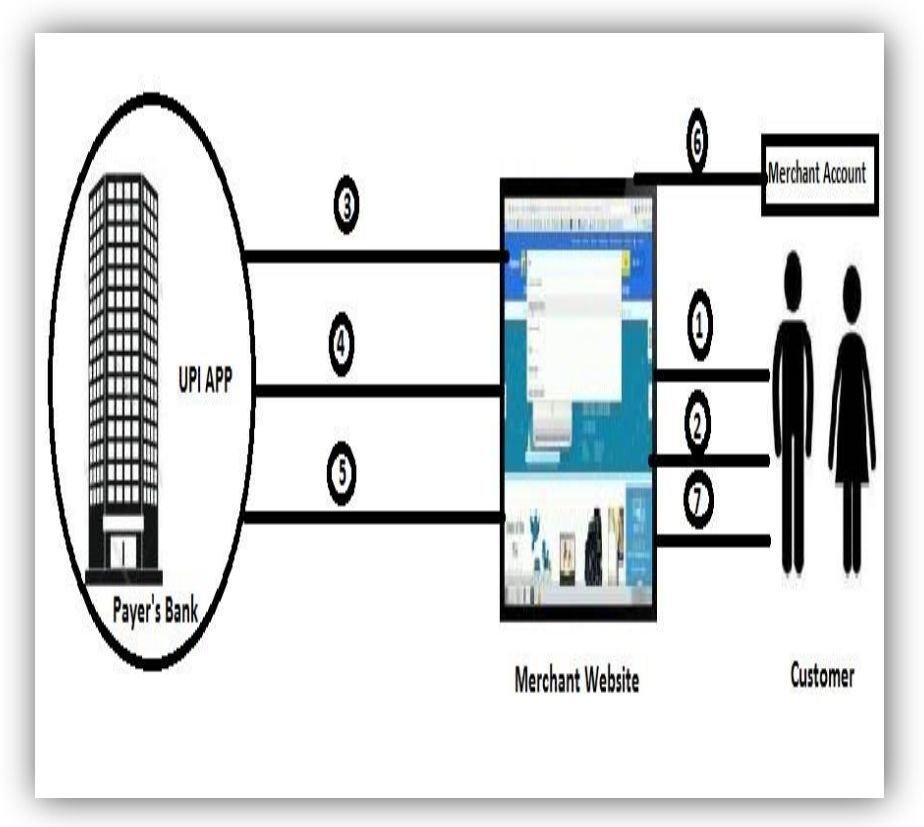


Figure 2: UPI Payment Model

\section{CONCLUSION}

The modern payment models are the fastest and secured payment methods which reduces the use of paper works and time for every common individual, it also enhance the scope of digital India. It also should make the transaction free from vulnerable merchant attacks.

\section{REFERENCES}

1. Majid Taghiloo,(October 2010) 'Cashless Digital Payment'-International Journal of Ubi Comp (IJU), Vol.1, No.4.

2. Dr Neetu Kumari,(2011) 'Cashless Payment: A Behavioral Change To Economic Growth'International Journal of Scientific Research and Education, ISSN(e) 2321-7545.

3. Nikhil Khandare, (Nov-Dec 2013),'SECURITY OF ONLINE ELECTRONIC TRANSACTIONS' International Journal of Technical Research and Applications e-ISSN: 2320-8163, www.ijtra.com Volume 1, Issue 5, PP. 53-58

4. Plateaux A., Lacharme P., Coquet V., Vernois S., Murty K., Rosenberger C, (2013) 'An e-payment Architecture Ensuring a High Level of Privacy Protection' PP. 3-5.

5. L. Ching, V. Vijay, W. Yan, and P. Vineet, (2005. CEC 2005) 'Trust enhanced security for mobile agents, ECommerce Technology'- Seventh IEEE International Conference on, 2005, pp. 231-238

6. Fadi Aloul, Syed Zahidi, Wassim El-Hajj (2009) "Two Factor Authen tication Using Mobile Phones" pp. 3138.

7. Ravi B.Kalakota and Andrew B.Whinston ( 2011) "Frontiers of Electronic Commerce" - Addison Wesley, Pearson Education, Asia pp. 3-8.

8. In: Zia T., Zomaya A., Varadharajan V., Mao M. (2013) 'Security and Privacy in Communication Networks'- SecureComm pp. 63-69.

9. Mohammad Ali Agheli , (October 2010) 'Cashless Digital Payment'-International Journal of Ubi Comp (IJU), Vol.1, No.4.
10. Mohammad Reza Rezaeinezhad , (October 2010) 'Cashless Digital Payment'-International Journal of Ubi Comp (IJU), Vol.1, No.4.

11. Jhanvi Khanna, (2011) 'Cashless Payment: A Behavioral Change To Economic Growth'- International Journal of Scientific Research and Education, ISSN(e) 2321-7545.

12. Dr. B. B. Meshram (Nov-Dec 2013),'SECURITY OF ONLINE ELECTRONIC TRANSACTIONS' International Journal of Technical Research and Applications e-ISSN: 2320-8163, www.ijtra.com Volume 1, Issue 5, PP. 53-58 